Aloman 2015, 33(1), 15-24

Revista de Psicologia, Ciències de l'Educació i de l'Esport

ISSN: 1138-3194

Copyright (C) 2015

www.revistaaloma.net

\title{
Processos cognitius que intervenen en l'aprenentatge del llenguatge escrit i dislèxia
}

\author{
Ignasi Ivern \\ Universitat Ramon Llull
}

Rebut: 29-1-2015

Acceptat: 8-3-2015

Processos cognitius que intervenen en l'aprenentatge del llenguatge escrit i dislèxia

Resum. La lectura és una activitat complexa que involucra la interacció de dos processos essencials: el reconeixement de paraules escrites $i$ la comprensió. El primer procés, tot $i$ ser de nivell elemental, ha de funcionar de manera òptima perquè es pugui assolir el component de més alt nivell, que és la comprensió lectora. En aquest article es revisen els models cognitius més rellevants que expliquen el reconeixement de les paraules escrites i l'accés al lèxic. En primer lloc s'analitza la influència que poden exercir factors com les característiques ortogràfiques d'una llengua i les característiques de cada paraula en particular. En segon lloc es fa una revisió del model de doble ruta i les seves variacions (Coltheart, 1981; Coltheart et al., 2001) i del model connexionista de Triangle (Seidenberg \& McClelland, 1989; Seidenberg, 2007). Finalment, s'analitza la caracterització de la dislèxia prenent com a referència les aportacions dels models cognitius.

Paraules clau: reconeixement de paraules, accés al lèxic, lectura, models cognitius, dislèxia

\section{Cognitive processes involved in written language learning and dyslexia}

Summary. Reading is a complex activity that involves the interaction of two essential processes: the recognition of written words and the understanding thereof. The former of these processes, although it operates on an elementary level, must function optimally in order for a person to be able the higher level component, namely reading comprehension. This article features a review of the most important cognitive models that are relevant to these processes and that explain and that help explain the recognition of written words and lexical access. It begins by analyzing the possible influence exerted by factors such as the orthographical characteristics of a language overall and the characteristics of each word individually. It goes on to review the dual-route model and variations upon it (Coltheart, 1981; Coltheart et al., 2001), as well as the Triangle connectionist model (Seidenberg \& McClelland, 1989; Seidenberg, 2007). It concludes with an analysis of the characterization of dyslexia conducted within the frame of reference of these cognitive models.

Keywords: word recognition, lexical access, reading, cognitive models, dyslexia

Correspondència

Ignasi Ivern

Facultat de Psicologia, Ciències de l’Educació i de l’Esport

Blanquerna.

Universitat Ramon Llull

C/ Císter, 34

08022 Barcelona

ignasiip@blanquerna.url.edu 


\section{Introducció}

El llenguatge escrit apareix recentment en el context de l'evolució humana. L'Homo ergaster, considerat per a molts autors el primer homínid de debò, té característiques anatòmiques bastant similars a les nostres, quant a alçada, mida del cervell i condició bípeda. L'asimetria hemisfèrica està clarament desenvolupada i els lòbuls frontals i temporals també; en particular, l'àrea de Broca (Holloway, Broadfield, Yuan, Schwartz \& Tattersall, 2004). Possiblement és capaç de produir de manera creativa i intencional expressions corporals que reflecteixen representacions internes. Podríem dir que amb l'ergaster assistim al naixement del signe. Però, la humanitat, en el ple sentit de la paraula, queda configurada definitivament amb l'emergència de l'Homo sapiens a l'Àfrica fa uns 200.000 anys. Amb molta probabilitat és aleshores quan apareix el llenguatge oral. La major part d'autors coincideixen a assenyalar que les primeres formes de comunicació humana van ser gestuals i els gestos vocals, en particular, es van incorporar molt tard en l'evolució dels homínids, segurament amb el sorgiment de la nostra pròpia espècie a través del «sistema mirall» (Corballis, 2010).

Els éssers humans enraonem des de fa més de 100.000 anys, pel cap baix, però l'escriptura va aparèixer fa només uns 5.000 anys $^{1}$, la qual cosa no significa que la població general hagi llegit durant aquest període de temps. De fet, fins fa pocs segles l'accés al llenguatge escrit ha estat reservat a una minoria i encara avui dia hi ha molts països amb alts índexs d'analfabetisme. L'escriptura és una invenció molt recent que va sorgir per garantir la transmissió cultural i assegurar que els coneixements poguessin passar d'una generació a l'altra. Aquest nou sistema de comunicació va introduir una novetat important: així com el llenguatge oral s'adquiria sense esforç, de manera «natural», el llenguatge escrit, en canvi, exigia una instrucció formal.

Des d'una perspectiva evolutiva, observem que hi ha processos i estructures que tots els individus de l'espècie humana han anat forjant al llarg de mil-lennis i n'hi ha d'altres de «nouvinguts» a la ment que tot just s'han universalitzat en els darrers centenars d'anys. En altres paraules, el pes de l'evolució lingüística resideix en el llenguatge oral, el qual està associat a l'oïda, no a la visió. L'aprenentatge de la llengua escrita ha impulsat la connexió entre la informació visual i un dispositiu cerebral «dissenyat» a per analitzar sons. Així, doncs, el processament auditiu juga un paper molt important tant en el llenguatge oral com en l'escrit. Tot plegat ens anima a desafiar la intuïció i, en contra del sentit comú, a afirmar amb certa provocació que «llegim amb les orelles». Al llarg d'aquest article mirarem d'argumentar aquesta idea, que, en termes més acadèmics, vindria a ser que «el component fonològic és clau en el procés lector».

La lectura és una activitat complexa que involucra

\footnotetext{
${ }^{1}$ Un dels primers sistemes d'escriptura coneguts és la cuneïforme,
} creada pels sumeris de la Baixa Mesopotàmia fa prop de 5.200 anys. la interacció de dos processos essencials: a) el reconeixement de paraules escrites (component de processament de baix nivell) i b) la comprensió (component de més alt nivell que, més enllà dels aspectes fonològics, implica la integració d'aspectes morfosintàctics, semàntics i pragmàtics). El primer procés no solament s'ha de fer correctament; en la persona experta, a més, ha de ser en gran mesura automàtic. Com diuen Demont i Gombert (2004), més que el domini grafofonològic i ortogràfic necessari per al reconeixement de les paraules, és el grau d'automatisme el factor més determinant d'èxit per a una lectura eficaç. El nivell d'atenció que exigeix el reconeixement de paraules a un bon lector és baix, de manera que pot dedicar tots els recursos disponibles a la comprensió del text. En canvi, en el mal lector, la identificació de paraules funciona malament, per la qual cosa ha de dirigir la seva atenció en excés a aquesta tasca en perjudici de la comprensió.

Sense una mecànica adequada no es pot assolir l'objectiu fonamental del procés lector que és la comprensió lectora. Si un infant no pot llegir amb fluïdesa a finals de $4 \mathrm{t}$ de Primària, el trajecte acadèmic serà molt més difícil i amb més probabilitats de fracassar. A partir de 5è, els estudiants utilitzen les seves destreses lectores com una eina per a l'aprenentatge d'altres matèries. Per tant, en darrera instància, l'objectiu més important és passar d'aprendre a llegir a «llegir per a aprendre».

\section{Factors que influeixen en el reconeixement de les paraules escrites}

Abans d'endinsar-nos en els processos cognitius que intervenen en l'aprenentatge del llenguatge escrit, analitzarem alguns factors que poden exercir una influència decisiva en el reconeixement de les paraules, agrupats en dos apartats: a) característiques ortogràfiques de les llengües i b) característiques de les paraules.

\section{Característiques ortogràfiques de les llengües: opacitat/transparència i complexitat sil-làbica}

Quan parlem d'opacitat versus transparència, fem referència al grau en què cada lletra o grafema es correspon amb un so o fonema. Així, doncs, el terme opac es reserva per a aquells casos en el quals no s'estableixen correspondències úniques entre sons i lletres, sinó que un fonema pot estar representat per més d'una grafia i, a l'inrevés, una grafia pot estar relacionada amb diversos fonemes. Pel que fa a la complexitat sil-làbica, ens referim a la major o menor proporció d'estructures sil-làbiques CVC (consonant-vocal-consonant) en una llengua davant de la proporció de síl-labes amb estructures CV (consonant-vocal). En el marc de l'European Cooperation in Science and Technology (COST) es va dur a terme un estudi sobre les característiques de diferents llengües alfabètiques europees per analitzar la influència de l'opacitat ortogràfica i la complexitat sil-làbica en l'aprenentatge de la lectoescriptura (Niessen, Frith, Reitsma, \& Öhngren, 2000). En la taula 1 podem veu- 
Taula 1. Classificació d'una mostra de llengües alfabètiques europees en funció de l'opacitat ortogràfica i de l'estructura sil.làbica (Seymour, Aro, \& Erskine, 2003).

\begin{tabular}{|c|c|c|c|c|c|c|}
\hline & & & & Opacitat & & \\
\hline & & & Transparència & & Opacitat & \\
\hline \multirow{6}{*}{$\begin{array}{l}\text { Estructura } \\
\text { sil·làbica }\end{array}$} & \multirow{3}{*}{ Simple } & Finès & Grec & Portuguès & Francès & \\
\hline & & & Italià & & & \\
\hline & & & Castellà & & & \\
\hline & \multirow{3}{*}{ Complexa } & & Alemany & Holandès & Danès & Anglès \\
\hline & & & Noruec & Suec & & \\
\hline & & & Islandès & & & \\
\hline
\end{tabular}

re aquest conjunt de llengües que, tot i compartir l'ortografia alfabètica, posseeixen característiques diferents. En un cantó hi trobem el finès, com a exemple de màxima transparència ortogràfica i simplicitat en l'estructura sil-làbica i, en l'altre extrem, l'anglès, exemple de màxima opacitat i complexitat.

Seymour, Aro i Erskine (2003) mostren que els infants de la majoria dels països europeus assoleixen nivells bàsics de lectura abans de finalitzar el primer any escolar. Tanmateix es constata un cert retard en algunes llengües com el francès, el portuguès, el danès i, sobretot, l'anglès. Aquests autors atribueixen la responsabilitat d'aquest endarreriment a les diferències lingüístiques fonamentals en complexitat sil-làbica i opacitat ortogràfica. La complexitat sil-làbica afecta selectivament els processos de descodificació, mentre que l'opacitat ortogràfica afecta tant la lectura de paraules com de pseudoparaules ${ }^{2}$. El procés d'aprenentatge de l'anglès és significativament més lent que el de la resta de llengües. Els nens finlandesos van aprendre a llegir, com a mínim, dues vegades més ràpid que els aprenents d'anglès. La hipòtesi de Seymour, Aro i Erskine (2003) és que les ortografies opaques impliquen recórrer a dos processos (logogràfic + alfabètic), la qual cosa requereix més del doble de temps que el procés únic (alfabètic) necessari per a l'aprenentatge de la lectura en una ortografia transparent. L'estudi longitudinal de Caravolas, Lervag, Defior, Málková i Hume (2013) també evidencia que el desenvolupament de les habilitats lectores al principi segueix un ritme més lent en l'anglès que en llengües més transparents com el castellà i el txec. De totes maneres, McClung (2012) assenyala que cap a 4t de Primària el paper perjudicial de l'opacitat ortogràfica disminueix clarament en els lectors competents i qualificats. Es creu que l'opacitat ortogràfica té un efecte més poderós que la complexitat sil-làbica en els inicis de l'aprenentatge del llenguatge escrit. Tot i això, sembla ser que l'estructura sil-làbica juga un paper important en la consciència fonològica. Segons Duncan, Colé, Seymour i Magnan (2006), els parlants de llengües amb estructures sil-làbiques simples mostren una consciència fonològica major que els

\footnotetext{
${ }^{2}$ Al llarg del text utilitzarem el terme pseudoparaula per a al-ludir indistintament a «pseudoparaula» i a «no paraula». Ambdós termes fan referència a una seqüència de lletres que no constitueixen cap paraula. La diferència entre l'un i l'altre és que «pseudoparaula» és una paraula inexistent però versemblant i pronunciable.
}

de llengües amb una gran complexitat sil-làbica.

Ateses les diferències entre llengües, és evident que el mètode d'ensenyament-aprenentatge no pot ser el mateix per a tothom. El mètode fonètic pot ser idoni per a llengües transparents, mentre que les llengües més opaques, en les quals les correspondències entre grafemes i fonemes són més irregulars, necessiten recórrer a un mètode basat en el reconeixement global de les paraules.

\section{Característiques de les paraules: freqüència, edat d'adquisició, longitud i context}

A més de les propietats específiques d'una llengua, les característiques particulars de cada paraula també influeixen en el reconeixement d'aquestes i en l'accés al lèxic. Des de Foster (1976), es constata amb claredat que les paraules d'ús freqüent es reconeixen més ràpidament que les paraules poc familiars. Existeixen diferents hipòtesis que expliquen aquest fenomen. Una de les més clàssiques planteja que les paraules contingudes en el lèxic -el magatzem intern del lector- són activades a partir d'un mecanisme que recull informació visual o auditiva anomenat «logogén» (Morton, 1979). Aquest mecanisme acumula informació fins a arribar a un llindar a partir del qual la paraula és reconeguda. La idea bàsica seria que, pel fet d'utilitzar més sovint una paraula, el llindar disminueix i, per tant, requerim menys temps per a recuperar-la. Altres hipòtesis proposen amb relativa senzillesa que les paraules més freqüents es reconeixen abans perquè han estat processades més vegades. L'efecte freqüència s'observa preferentment en les paraules-contingut (noms, verbs i adjectius) i no tant en les paraules-funció (conjuncions, determinants i preposicions), la qual cosa suggereix que els mecanismes de reconeixement estan relacionats amb la categoria sintàctica de la paraula.

La variable freqüència està molt relacionada amb l'edat d'adquisició, el moment en el qual una paraula es va aprendre per primera vegada. Habitualment les primeres paraules que aprenen els infants són les més comunes, tot i que, com diu Harley (2008), existeixen cèlebres excepcions com, per exemple, gegant, terme que s'aprèn precoçment i que, tanmateix, és d'una freqüència relativament baixa. Les paraules que s'aprenen primer, al llarg de la vida es llegeixen més ràpid $\mathrm{i}$ amb més precisió que les que s'aprenen més tard. 
Una altra variable que en principi sembla exercir una influència òbvia és la longitud. No ens hauria de sorprendre que les paraules curtes siguin reconegudes més ràpidament que les llargues. De totes maneres, a nivell metodològic el tema és complex. Existeixen diverses formes de mesurar la longitud de les paraules (nombre de lletres, nombre de síl-labes i temps que es tarda a dir la paraula) i resulta molt difícil identificar l'efecte de la longitud independentment del de la freqüència (Harley, 2008).

Per acabar, hi ha un conjunt de variables que podríem reunir sota l'epígraf «context» que afecten el reconeixement de paraules. En primer lloc, el veïnatge. Hi ha paraules que tenen un gran nombre de paraules similars a nivell ortogràfic, mentre que d'altres, de freqüència comparable, en tenen poques. S'ha descobert que el nombre elevat d'aquestes paraules que anomenem veïnes, sorprenentment, en comptes de generar competència en facilita el reconeixement (Andrews, 1997). A qui més beneficia aquest fenomen és a les paraules de baixa freqüència. En tasques de denominació i decisió lèxica, l'execució és més ràpida per a les paraules de baixa freqüència amb molts veïns ortogràfics. En segon lloc, voldríem destacar que el temps de reacció es menor quan una paraula ha estat presentada amb anterioritat en el text. Sembla lògic que el fet d'haver vist primer una paraula faciliti un reconeixement més ràpid, però l'interessant és que aquest fenomen té un efecte persistent durant hores o fins i tot durant un més temps més llarg. I, finalment, el darrer aspecte a considerar és la facilitació contextual a nivell semàntic. El temps de reconeixement es redueix quan la paraula va precedida d'una altra paraula que hi està associada semànticament. A nivell experimental, el fet d'identificar les paraules més fàcilment quan es troben en un context amb altres paraules de significat semblant que no pas quan apareixen ailladament planteja una paradoxa interessant: el procés és més ràpid tot $\mathrm{i}$ que disposem de més informació a processar. Els models que han pogut donar una explicació més acurada d'aquest fenomen són aquells que postulen un processament en paral-lel, en contra dels que defensen un processament serial.

La influència de totes les característiques que hem comentat en aquest apartat no es pot separar d'una variable fonamental: l'experiència o la destresa del lector. Així, per exemple, la longitud exercirà una influència notòria en els aprenents de lectors, perquè el procediment que segueixen per a llegir és «indirecte», basat en una descodificació «lletra per lletra». D'altra banda, els lectors experimentats, llegiran amb més o menys rapidesa en funció de l'efecte freqüència, ja que fan una lectura «directa» de les paraules. A continuació, aprofundirem en aquests processos a partir dels models cognitius més rellevants que existeixen fins ara.

\section{Models cognitius i vies d'accés al lèxic en el llenguatge escrit}

El primer esglaó d'aquest llarg camí vers el domini del llenguatge escrit comença amb el reconeixement de les paraules. Existeixen diferents models per explicar el procés lector. Malgrat les diferències entre uns i altres, tots coincideixen en el fet de descriure tres sistemes de processament: l'ortogràfic, encarregat de la identificació de les lletres que componen les paraules; el fonològic, encarregat de recuperar els sons; i el semàntic, encarregat de recuperar el significat de les paraules (Cuetos \& Domínguez 2012). Aquests models es diferencien entre ells en l'organització d'aquests processos i, especialment, en la manera com interactuen durant la lectura de paraules. Els uns segueixen l'enfocament del processament de la informació i els altres la tradició de la teoria connexionista. Els primers plantegen una anàlisi en sèrie i seqüencial dels processos cognitius, seguint la metàfora computacional, la qual cosa implica que alguns processos dirigeixen altres processos jeràrquicament i que el sistema cognitiu en el seu conjunt té una organització modular. Per contra, els segons, inspirats per la metàfora cerebral, emfasitzen el processament en paral-lel basat en el funcionament de les neurones, sense cap organització jeràrquica clara i postulen que el sistema cognitiu no es pot descompondre en parts, no és modular.

Com a models paradigmàtics sobre el procés lector de cada un d'aquests enfocaments volem destacar els següents: a) Model de doble ruta (Coltheart, 1981) i b) Model connexionista de triangle (Seidenberg \& McClelland, 1989).

\section{Model de doble ruta}

El Model de doble ruta o Model dual per a la lectura planteja en essència que en el procés de reconeixement d'una paraula fins que s'arriba a l'accés al lèxic hi poden intervenir dues vies diferents: 1) la via lèxica, també anomenada via directa o ruta visual i 2) la via sublèxica, també anomenada via indirecta o ruta fonològica.

En la via lèxica es produeix un reconeixement immediat de la paraula pel fet de tenir-la representada mentalment, de la mateix manera que reconeixeríem un dibuix o un objecte. Arribem al significat a través de la representació ortogràfica de la paraula. El recorregut és breu: analitzem globalment la paraula escrita, la reconeixem en el lèxic visual i finalment accedim al significat emmagatzemat en el sistema semàntic. Aquesta via permet llegir paraules conegudes amb extraordinària rapidesa, però, tanmateix, no permet llegir paraules desconegudes o pseudoparaules. En la figura 1 podem observar el recorregut que segueix la via lèxica des de la paraula escrita fins al sistema semàntic.

En la via sublèxica o fonològica l'itinerari és més llarg. Analitzem la paraula escrita i, un cop reconegudes les lletres en el magatzem de grafemes, se segueix un procés de conversió grafema-fonema i se'ls assigna el so corresponent. Després reconstruïm la forma que correspon a la parla, la reconeixem en el lèxic auditiu i finalment accedim al significat que es troba en el sistema semàntic. El procés de reconeixement de la paraula i d'accés al lèxic és més lent, però permet llegir 
Figura 1. Accés al significat per via lèxica (Cuetos, Rodríguez, Ruano \& Arribas, 2009)

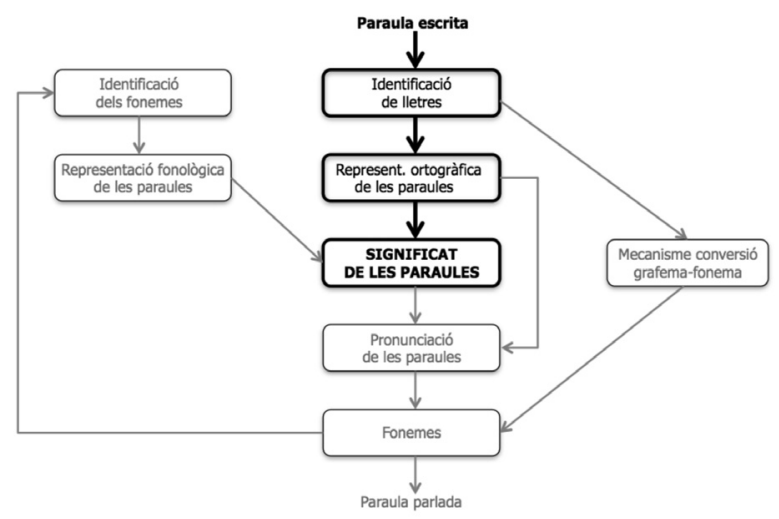

paraules desconegudes i pseudoparaules. En la figura 2 podem observar la volta que fa aquest circuit.

Un dels indicadors més clars per a saber la ruta de processament que s'està utilitzant per a llegir una paraula és el temps que es tarda a descodificar-la. La via fonològica sempre és més lenta que la via lèxica. Les pseudoparaules i les paraules desconegudes només poden ser llegides per aquesta via, de manera que podem servir-nos-en per a explorar el rendiment a nivell de processament fonològic. Quan el lector lexicalitza una pseudoparaula, tot transformant-la en paraula, o canvia, per equivocació, una paraula real de baixa freqüència per una altra de més alta freqüència, significa que utilitza la via lèxica. Quan no hi ha prou habilitat en la ruta fonològica, aquesta mena d'errors són freqüents, tot afectant l'exactitud lectora. Pel que fa a l'estructura de la paraula, quan llegim per via lèxica, el nivell sil-làbic no comporta que hi hagi variacions de temps, mentre que, quan ho fem per via fonològica, el temps augmenta significativament en funció de la longitud de la paraula.

Arribats a aquest punt, resulta interessant relacionar el model de la doble ruta amb una de les propostes teòriques més conegudes sobre l'aprenentatge de la lectura com és la de Frith $(1983 ;$ 1985). L'autora planteja que, per tal que l'infant esdevingui un lector hàbil, ha de passar pels tres estadis següents, caracteritzats per l'estratègia que predomina en cada un:

1. Logogràfic: Al principi l'infant reconeix globalment la paraula a partir de la seva forma; és com si fos un dibuix. Així reconeix les paraules familiars per les seves característiques gràfiques.

2. Alfabètic (via fonològica): Quan ha d'augmentar el seu repertori de paraules, aquestes ja no poden ser llegides pel mateix mecanisme i es fa necessari procedir establint correspondències entre grafemes $i$ fonemes.

3. Ortogràfic (via lèxica): Finalment, és capaç d'identificar les paraules sense necessitat de recórrer a cap anàlisi fonològica. Les reconeix per les seves especificitats ortogràfiques.

Sense allunyar-nos gaire dels postulats de Frith (1985), han sorgit altres propostes com les de Seymour i les d'Ehri que també plantegen un desenvolupament
Figura 2. Accés al significat per via fonològica (Cuetos, Rodríguez, Ruano \& Arribas, 2009)

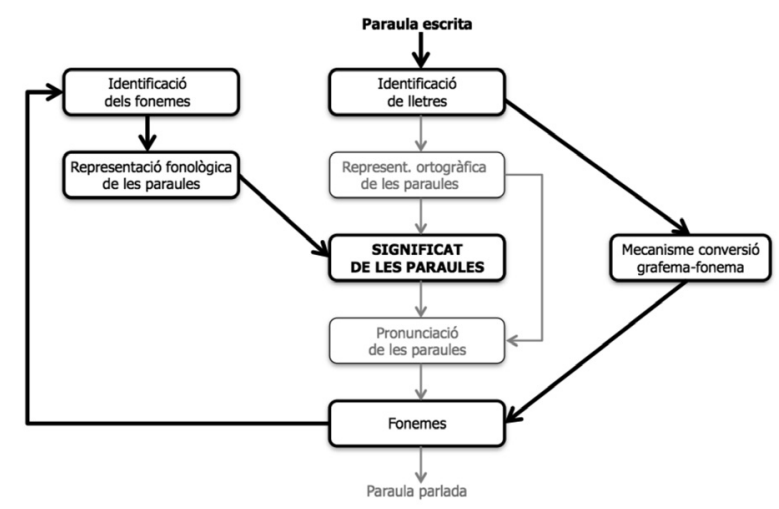

per etapes (Seymour \& Evans, 1994; Seymour \& Duncan, 1997; Duncan, Seymour \& Hill, 1997; Seymour, Duncan \& Bolik, 1999; Ehri, 1999; Ehri, 2005). Tots aquests models no estan exempts de crítiques, no tan sols per la influència decisiva que poden jugar qüestions com la llengua o el mètode d'ensenyament-de les quals parlarem més endavant-, sinó també perquè en els darrers anys la psicologia cognitiva s'ha anat allunyat de la idea piagetiana basada en un desenvolupament en estadis amb canvis globals que abasten dominis amplis i s'ha apropat a les tesis de Karmiloff-Smith (1992) basades en dos conceptes nous: la idea de «canvis de fase recurrents» i l'existència de «microdominis» (Ivern \& Perinat, 2013). En aquest sentit, els crítics amb els anteriors models expliquen l'aprenentatge de la lectura no tant per etapes, com sostenen Frith, Seymour o Ehri, sinó per canvis basats en ítems, tal com defensa la teoria de l'autoaprenentatge (Share, 1995, 1999). Segons Share (2008), l'habilitat per a reconèixer les paraules escrites dependria més de com fossin de familiars per al lector que no pas de l'estratègia predominant en una fase determinada.

Més enllà de les febleses d'unes propostes i altres, el que és acceptat per tothom és que, a mesura que millora la competència lectora, la via lèxica adquireix un paper rellevant, mentre que la via fonològica passa a tenir un paper secundari, reservat a situacions molt concretes com ara la lectura de paraules desconegudes. Aquesta evolució implica un procés d'automatització del reconeixement de paraules que es tradueix en un augment extraordinari de la velocitat lectora i en un desplaçament de l'atenció vers la comprensió. En procedir automàticament, el lector pot abocar tots els seus recursos cognitius a atendre les qüestions més importants; el significat i la intencionalitat del text. L'efecte Stroop exemplifica perfectament com automatitzem la lectura de paraules. Quan hem d'anomenar el color amb què està escrita una paraula, llegim la paraula involuntàriament, sense remei. Aquesta interferència posa de manifest que llegim i identifiquem abans les paraules que els colors, perquè la resposta verbal és automàtica, mentre que la denominació dels colors requereix control conscient. Un cop hem après a llegir, no podem deixar de fer-ho. 


\section{Model de doble ruta en cascada}

Els models són instruments metodològics que permeten representar de manera simplificada realitats complexes i serveixen per a provar teories. A finals dels anys vuitanta, els models cognitius passen de ser diagrames de caixes i fletxes, amb l'objectiu d'explicar els processos mentals d'una manera gràfica, a esdevenir programes informàtics que simulen aspectes detallats del comportament. Així, doncs, per exemple, els models de lectura poden ser «ensenyats» per a aprendre a reconèixer sèries de lletres $\mathbf{i}$ «calcular» els seus significats o la seva pronunciació. Aquests nous models s'han convertit en una eina fabulosa per a desenvolupar i provar idees sobre com llegeixen les persones, d'acord amb un marc teòric determinat.

El Model de doble ruta va ser revisat per Coltheart, Rastle, Perry, Langdon i Ziegler (2001), introduint processos interactius, a més dels serials. Aquest nou model anomenat «Model de doble ruta en cascada o DRC» és un model informàtic de la teoria dual, que pot executar les dues tasques més habitualment utilitzades per a estudiar la lectura: decisió lèxica i lectura en veu alta. Malgrat el seu nom, de fet consta de tres rutes (vegeu figura 3). D'una banda hi ha la ruta lèxica, que se subdivideix en ruta lèxica semàntica i ruta lèxica no semàntica i, de l'altra, hi ha la ruta de conversió grafema-fonema. Els components de les rutes contenen un conjunt d'unitats simbòliques (paraules, en el cas del «lèxic ortogràfic» o lletres, en el component «unitats de lletra»), que interactuen de dues maneres possibles: inhibint o excitant. A través de la inhibició, resulta que l'activació d'una unitat dificulta l'activació de les altres. Per contra, a través de l'excitació, l'activació d'una unitat contribueix a l'activació d'altres unitats. En la figura 3 podem veure els enllaços excitadors entre unitats, representats per fletxes, i els inhibidors, representats per cercles.

A nivell experimental, el model de la doble ruta es veu reforçat quan s'analitza la influència de factors que intervenen en la lectura, com la freqüència i la regularitat (Seidenberg, Waters, Barnes \& Tanenhaus, 1984).

Figura 3. Model de doble ruta en cascada -DRC- (Coltheart et al. 2001)

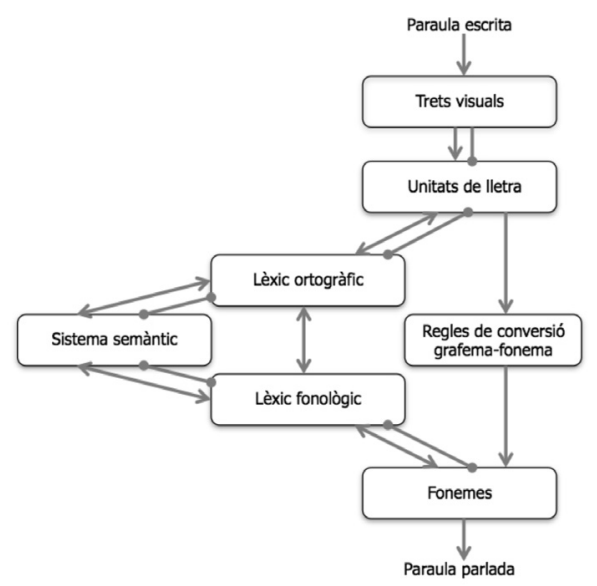

Pel que fa a l'àmbit clínic, Coltheart, Curtis, Atkin \& Haller (1993) aporten dades, des de la neuropatologia, que també donen suport a aquest model. Aquests autors descriuen el cas de persones que poden llegir pseudoparaules i, tanmateix, no són capaces de llegir paraules conegudes i, a l'inrevés, persones que llegeixen paraules, fins i tot irregulars, però no pseudoparaules o paraules desconegudes. Avui dia, el model de doble ruta amb totes les seves diferents versions està considerat el més influent d'entre tots els models que existeixen per a explicar el procés lector. Tot i això, mostra febleses fruit de la dificultat per a explicar tota la complexitat del llenguatge amb «caixes i fletxes» seguint una metàfora computacional. Algunes modificacions introduides en els darrers anys l'apropen als models connexionistes (Serra, 2013), caracteritzats per una major interactivitat i per la descripció de processos en parallel. D'entre aquest tipus de models, volem destacar el Model triangular de reconeixement de paraules (Seidenberg \& McClelland, 1989).

\section{Model connexionista de triangle}

Els models connexionistes estan plantejats com a grans xarxes d'elements de processament, similars a les xarxes neuronals, de manera que són capaços d'aprendre a realitzar tasques com la lectura de paraules o el reconeixement d'objectes. El Model de triangle considera que el procés lector consta de tres dominis representatius: Ortografia, Fonologia i Semàntica, connectats entre ells mitjançant enllaços de retroalimentació de forma triangular (vegeu figura 4). Entre aquests dominis hi ha el que els autors anomenen les unitats ocultes, les quals contribueixen a reflectir millor la complexitat dels problemes que el model hauria de resoldre.

Tot i la creença predominant que les paraules s'emmagatzemen en un lèxic mental similar a un diccionari amb entrades individuals, en aquest model, a diferència dels anteriors, no hi ha entrades lèxiques. La informació sobre les paraules es troba distribuïda per la xarxa i cada paraula es representa com un patró d'activació únic sobre conjunts d'unitats. En paraules

Figura 4. Model Triangular de reconeixement de paraules (Seidenberg \& Mc Clelland, 1989)

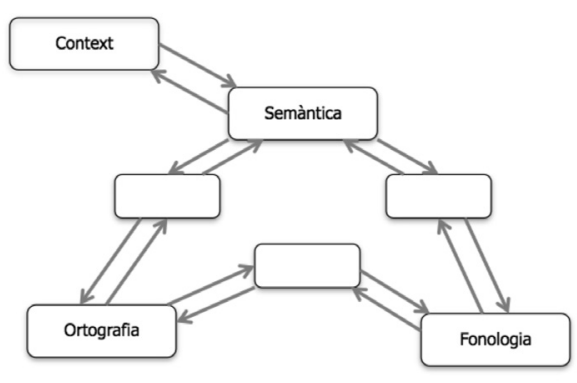


del mateix Seidenberg (2007), cal anar més enllà de la intuïció. Els models connexionistes aborden la naturalesa dels mecanismes subjacents a la lectura a un nivell en el qual la intuïció no hi penetra fàcilment, perquè es tracta d'explicar processos que en gran mesura són no controlats. Les paraules més freqüents es reconeixen primer, perquè han estat processades més vegades. La força de les connexions entre aquestes s'incrementa a través de la repetició dels patrons d'activació mitjançant la pràctica. Com més cops siguin processades, més gran és la connexió. Així, podríem dir que les ponderacions de les connexions no les estableix el model, sinó que són fruit de l'aprenentatge.

Aquest model és capaç d'explicar com els lectors reconeixen sèries de lletres com a paraules i com aquestes són pronunciades. Podem llegir directament de l'ortografia a la semàntica o indirectament a través de la fonologia. Les pseudoparaules, en no tenir representació semàntica, només es poden llegir a través de la connexió ortografia-fonologia; no hi ha una ruta que impliqui regles de conversió grafema-fonema. De la mateixa manera que en el model de doble ruta revisat, també existeix una via de l'ortografia a la fonologia a través de la semàntica. Besner, Twilley, McCann i Seergobin (1990) i Coltheart et al. (1993) van criticar les primeres formulacions d'aquest model perquè deixava molts interrogants sense resposta; un exemple el trobaríem en explicar els diferents tipus de dislèxia. Per aquesta raó ha sofert diferents revisions que han millorat l'explicació sobre alguns aspectes com la presa de decisions lèxiques i la pronunciació de pseudoparaules (Harley, 2008). Posteriorment Harm i Seidenberg (2004) van reformular el model perquè totes les parts del sistema funcionessin de manera simultània i contribuïssin a l'activació del significat.

Les últimes versions dels models connexionistes intenten incorporar les aportacions del Model de doble ruta o Model dual, la qual cosa ha donat lloc a l'anomenat Model dual connexionista (Perry, Ziegler \& Zorzi, 2007). Tanmateix, el Model de doble ruta continua essent el més àmpliament acceptat, ja que proporciona una explicació versemblant sobre la lectura hàbil, el reconeixement de les paraules i les pseudoparaules i l'aprenentatge de la lectura. I, a més, explica i ajuda a comprendre les diferents manifestacions de la dislèxia evolutiva i adquirida.

\section{La dislèxia des de la perspectiva cognitiva}

Un cop analitzats els processos cognitius i els factors que intervenen en el primer esglaó de la lectura -que és el reconeixement de paraules-, passem ara, de manera molt simplificada, a descriure les disfuncions que hi poden haver agrupades sota la categoria diagnòstica de dislèxia. Tot i que el debat sobre la naturalesa de la dislèxia està plenament obert, hi ha consens a definir-la com una dificultat específica d'aprenentatge del llenguatge escrit d'origen neurobiològic, que és inesperada atesa la capacitat intel-lectual, la motivació i l'accés a una instrucció adequada. A més, aquest dèficit està associat a dificultats socials i emocionals que augmenten amb l'edat (Shaywitz, Morris \& Shaywitz, 2008; Melby-Lervag, Lyster \& Hulme, 2012).

En termes de models, els problemes dels individus són deguts a la dificultat per a adquirir el domini de la ruta lèxica o de la ruta sublèxica. En la dislèxia adquirida, podem trobar símptomes qualitativament oposats entre un individu i un altre, la qual cosa suggereix una classificació nítida amb subtipus diferents. Tanmateix, en la dislèxia de desenvolupament o evolutiva això no es produeix de la mateixa manera. Si el sistema de classificació dels subtipus de dislèxies adquirides podria ser discret, el de les dislèxies evolutives ha de ser continu, a causa del nombre pràcticament inexistent de subjectes que manifesten patrons deficitaris purs. De fet, els resultats obtinguts fins ara mostren que la majoria de persones amb dislèxia tenen problemes amb totes dues rutes (Jiménez, 2012).

A continuació presentem els subtipus de dislèxia evolutiva més reconeguts i la seva relació amb els models cognitius desenvolupats en aquest article:

Dislèxia fonològica. Les persones amb dislèxia fonològica són capaces de llegir bé paraules familiars i, per tant, d'alta freqüència, independentment de la seva longitud, però, en canvi, tenen dificultats per llegir paraules desconegudes, poc habituals i pseudoparaules. Des de la perspectiva del Model de doble ruta, aquestes dificultats s'explicarien per una alteració en la via sublèxica que afectaria els mecanismes de conversió grafema-fonema. Arran d'aquesta disfunció, els nens llegeixen a través de la via lèxica com a estratègia per a compensar les seves dificultats. Això comporta errors habituals com les lexicalitzacions -convertir les pseudoparaules en paraules-, errors visuals i equivocacions fruit de llegir la part de la paraula que coneixen i inventar-se la resta. Les errades són més habituals en les paraules-funció que en les paraules-contingut (Jiménez, 2012). Pel que fa al model de triangle, aquest tipus de dislèxia s'interpreta com una alteració en la connexió de l'ortografia a la fonologia, de manera que els individus tracten de llegir a través del significat.

Dislèxia superficial. La lectura de les persones amb dislèxia superficial es caracteritza justament pel contrari del que els passa a les que tenen dislèxia fonològica. Els problemes els tenen amb la ruta lèxica, de manera que no són capaces de llegir les paraules globalment, utilitzant la descodificació fonològica per a totes les paraules, siguin familiars o no. Són capaces de llegir paraules regulars sense problemes (paraules familiars, desconegudes, i fins i tot pseudoparaules), però tenen serioses dificultats per a llegir paraules irregulars que no s'ajusten a les regles grafema-fonema (Cuetos \& Domínguez, 2012). La major part dels errors que cometen són regularitzacions. En llengües transparents com la castellana i, en bona mesura la catalana, sense paraules irregulars, això no té gaire incidència, però en llengües opaques com l'anglès aquest fenomen és significatiu. La característica més important d'un infant que ha de recórrer a la via fonològica per a llegir-ho tot és la lentitud, amb tots els problemes secundaris que comporta, 
com ara no respectar els signes de puntuació, perdre's durant la lectura, «esgotar-se» pel sobreesforç, etc.

Dislèxia mixta. Les persones amb dislèxia mixta comparteixen les dificultats descrites en els dos subtipus de dislèxies anteriors. Així, tenen problemes per llegir paraules desconegudes i pseudoparaules i també per llegir determinades classes de paraules com les abstractes, funcionals i verbs. Cometen errors visuals, derivatius i lexicalitzacions, però els errors més comuns són els semàntics. Substitueixen la paraula a llegir per una altra que no té cap relació ni ortogràfica ni fonològica però sí de significat; per exemple, llegeixen «sol» allà on diu «lluna» (Cuetos \& Domínguez, 2012). Des de la perspectiva del model de doble ruta, es produeix una alteració en les dues vies, total en la sublèxica i parcial en la lèxica. Des del model de triangle, també s'interpreta com una alteració que afecta a dues vies: la que connecta directament l'ortografia i la fonologia i la que ho fa a través de la semàntica.

La classificació dels diferents subtipus de dislèxia està clarament influenciada pel protagonisme de la llengua anglesa en la majoria d'investigacions. Tot i així, les recerques dutes a terme amb altres llengües més transparents mostren que també és vàlida, si bé hi ha diferències entre els subtipus a nivell de gravetat $i$ de freqüència en funció de la llengua (Cuetos, 2008; 2012). Des d'una perspectiva metodològica, l'avaluació dels processos de reconeixement de paraules no pot ser el mateix en unes llengües i en les altres. Com molt bé explica Jiménez (2012), en els estudis de parla anglesa quan es vol explorar el funcionament de la ruta visual, n'hi ha prou amb utilitzar mesures basades en «encerts» en lectura de paraules irregulars, i per mesurar el funcionament de la ruta fonològica, «encerts» en lectura de pseudoparaules. En canvi, llengües amb ortografia transparent com la castellana, no poden seguir aquestes mateixes pautes pel fet que no hi ha paraules irregulars. Així doncs, els estímuls a utilitzar sempre seran paraules familiars regulars i pseudoparaules. Com que totes dues poden ser llegides mitjançant un mateix procés basat en la descodificació fonològica, el paràmetre més adequat no és tant el nombre d'«encerts» sinó el «temps de latència» en lectura de paraules i pseudoparaules (Jiménez, Rodríguez \& Ramírez, 2009; Sprenger-Charrolles, Siegel, Jiménez \& Ziegler, 2011). S'entén que les paraules familiars seran llegides per la ruta directa, de manera que el temps invertit serà menor que el que requerirà la lectura de pseudoparaules, la qual obliga a una descodificació fonològica.

Sense deixar la perspectiva cognitiva, volem cloure aquest article destacant els elements claus que han generat més consens en la caracterització de la dislèxia i que poden explicar les disfuncions identificades a través dels models cognitius de les dificultats lectores en el nivell bàsic de reconeixement de paraules i accés al lèxic. Aquests són els següents:

- Consciència fonològica

- Memòria de treball

- Rapidesa de denominació

- Fluïdesa verbal
Hi ha un ampli acord en reconèixer que la immensa majoria de persones amb dislèxia tenen un dèficit fonològic (Ramus, 2003; Ramus, 2005; Shaywitz \& Shaywitz, 2005; Jiménez, Rodríguez \& Ramírez, 2009; Suárez \& Cuetos, 2012). La gran dificultat per accedir i processar la informació fonològica s'evidencia en la deficient automatització dels mecanismes de conversió grafema-fonema que manifesten.

La memòria de treball juga un paper important en l'aprenentatge de la lectura. Els problemes de memòria de treball en dislèctics estan relacionats amb el que Baddeley (1986) anomena en el seu model «llaç articulatori». Aquest component està especialitzat en retenir la informació verbal durant un breu període de temps. Conté un magatzem per a la informació fonològica i desenvolupa el repàs necessari que mantindrà temporalment aquesta informació abans no passi a la memòria a llarg termini (Baddeley, Gathercole \& Papagano, 1998).

La rapidesa de denominació és una capacitat decisiva en l'aprenentatge de la lectura que està relacionada amb la capacitat per accedir al lèxic (Cuetos, 2008). Els dislèctics són més lents en aquesta tasca, la qual cosa comporta majors dificultats per formar representacions de les paraules i accedir a elles.

Les investigacions sobre el llenguatge oral dels nens dislèctics assenyalen problemes de fluïdesa verbal, a nivell fonològic i semàntic. A tall d'exemple, el primer nivell podria ser citar el màxim nombre de paraules en un minut que comencin per la «m», mentre que el segon seria una tasca similar però d'acord a una categoria semàntica com «fruites». La majoria d'investigadors coincideixen en corroborar els problemes de fluïdesa a nivell fonològic, tanmateix n'hi ha que no constaten problemes en fluïdesa semàntica (Frith, Landerl \& Frith, 1995; Plaza, Cohen \& Chevrie-Muller, 2002).

De fet aquests quatre elements que caracteritzen el perfil d'allò que és disfuncional en l'individu amb dislèxia estan tots ells relacionats. La consciència fonològica, la memòria de treball, la rapidesa de denominació i la fluïdesa verbal, juntament amb els coneixements previs sobre el tema i l'actitud, són alhora predictors claus de l'eficàcia lectora i constitueixen els quatre eixos importants sobre els quals ha de pivotar la intervenció en problemes de lectoescriptura.

\section{Referències}

Andrews, S. (1997). The effect of orthographic similarity on lexical retrieval: Resolving neighborhood conflicts. Psychonomic Bulletin and Rewiew, 4, 439461.

Baddeley, A. D. (1986). Working memory. New York: Oxford University Press.

Baddeley, A. D., Gathercole, S. E. \& Papagano, C. (1998). The phonological loop as a language learning device. Psychological Review, 105, 158-173.

Besner, D., Twilley, L., McCann R. S. \& Seergobin, K. (1990). On the connection between connectionism 
and data: Are a few words necessary? Psychological Review, 97, 432-446.

Caravolas, M., Lervag, A. Defior, S., Málková, G. S. \& Hume, C. (2013). Different patterns, but equivalent predictors, of growth in reading in consistent and inconsistent orthographies. Psychological Science, 24(8), 1398-1407.

Coltheart, M. (1981). Disorders of reading and their implications for models of normal reading. Visible Language, 25(3), 245-286.

Coltheart, M., Curtis, B., Atkins, P. \& Haller, M. (1993). «Models of reading aloud: Dual route and paralleldistributed processing approaches». Psychological Review, 100, 589-608.

Coltheart, M., Rastle, K., Perry, C., Langdon, R. \& Ziegler, J. (2001). DRC: A dual route cascaded model of visual word recognition and reading aloud. Psychological Review, 108(1), 204-256.

Corballis, M. C. (2010). The gestural origins of language. WIREs Cognitive Science, 1, 2-7.

Cuetos, F. \& Domínguez, A. (2012). Lectura. A F. Cuetos (Ed.). Neurociencia del lenguaje (pp. 137-152). Madrid: Panamericana.

Cuetos, F. (2008). Psicología de la lectura. Madrid: Wolters Kluwer.

Cuetos, F., Rodríguez, B., Ruano, E. \& Arribas, D. (2009). PROLEC-R Batería de evaluación de los processos lectores, revisada. (2a edició). Madrid: TEA.

Demont, E. \& Gombert, J. E. (2004). L'apprentissage de la lecture: évolution des procédures et apprentissage implicite. Enfance, 56, 245-257.

Duncan, L. G., Colé, P., Seymour, P. H. K., \& Magnan, A. (2006). Differing sequences of metaphonological development in French and English. Journal of Child Language, 33(2), 369-99.

Duncan, L. G., Seymour, P. H. K. \& Hill, S. (1997). How important are rhyme and analogy in beginning reading? Cognition, 63(2), 171-208.

Ehri, L. (1999). Phases of development in learning to read words. A Oakhill, J. i R. Beard (eds.). Reading development and the teaching of reading. A psychological perspective. Oxford: Blackwell.

Ehri, L. (2005). Learning to read words: Theory, findings, and issues. Scientific Studies of Reading, 9, 167188.

Foster, K. I. (1976). Accesing the mental lexicon. A R. J. Wales i E. C. T. Walker (Eds.) New approaches to Language mechanisms. Amsterdam: North Holland.

Frith, U. (1983). Cognitive processes in spelling. London: Academic Press.

Frith, U. (1985). Beneath the surface of developmental dyslexia. Are comparisons between developmental and acquired disorders meaningful? A K. E. Patterson, J. C. Marshall \& M. Coltheart (Eds.). Surface Diyslexia. Neuropsychological and Cognitive Studies of Phonological Reading. London: LEA.

Frith, U., Landerl, K, \& Frith, C. (1995). Dyslexia and verbal fluency: more evidence for a phonological deficit: An International Journal of Research and Practice, 1, 1-10.
Harley, T. (2008). The psychology of Language: from data to theory. (3a edició). London: Psychology Press.

Harm, M. W., \& Seidenberg, M. S. (2004). Computing the meaning of words in reading: Cooperative division of labor between visual and phonological processes. Psychological Review, 111, 662-720.

Holloway, R. L., Broadfield, D. C. \& Yuan, M. S., Schwartz, J. H. \& Tattersall, I. (2004). The Human Fossil Record, vol. 3: Brain Endocasts-The Paleoneurological Evidence. New Jersey: John Wiley \& Sons.

Ivern, I. \& Perinat, A. (2013). La emergencia y evolución del metalenguaje en la infancia. Infancia y Aprendizaje, 36 (2), 163-180.

Jiménez, J. E. (Ed.) (2012). ¿Qué es la dislexia? A J. E. Jiménez (Ed.), Dislexia en español. Prevalencia e indicadores cognitivos, culturales, familiares y biológicos (pp. 25-44). Madrid: Pirámide.

Jiménez, J. E., Rodríguez, C. \& Ramírez, G. (2009). Spanish developmental dyslexia: Prevalence, cognitive profile and home literacy experiences. Journal of Experimental Child Psychology, 103, 167-185.

Karmiloff-Smith, A. (1992). Beyond modularity: a developmental perspective on cognitive science. Cambridge. Massachusetts: MIT Press [Traducció castellana Karmiloff-Smith, A. (1994). Más allá de la modularidad. Madrid: Alianza].

McClung, N. A. (2012). Effects of Orthographic Depth on Literacy Performance: Reading Comprehension Difficulties Across Languages. Tesi doctoral: Ph.D., University of California, Berkeley.

Melby-Lervag, M., Lyster, S. A. H. \& Hulme, C. (2012). Phonological skills and their role in learning to read: A meta-analytic review. Psychological Bulletin. DOI: $10.1037 / \mathrm{a} 0026744$.

Morton, J. (1979). Word recognition. A J. Morton \& J. C. Marshall (Eds.) Psycholinguistics Series 2: Structures and Processes. London: Elek. [Traducció castellana a F. Valle, Cuetos, F. J. M. Igoa \& S. del Viso (1990). Lecturas de psicolingüística. Vol. 1. Comprensión y producción del lenguaje. Madrid: Alianza].

Niessen, M., Frith, U., Reitsma, P., \& Öhngren, B. (2000). Learning disorders as a barrier to human development 1995-1999. Evaluation report. Technical Committee COST Social Sciences.

Perry, C., Ziegler, J. C., \& Zorzi, M. (2007). Nested incremental modelling in the development of computational theories: The CDP+ model of reading aloud. Psychological Review, 114, 273-315.

Plaza, M., Cohen, H. \& Chevrie-Muller, C. (2002). Oral language deficits in dyslexic children: weaknesses in working memory and verbal planning. Brain and Cognition, 48, 505-512.

Ramus, F. (2003). Developmental dyslexia: specific phonological dèficit or general sensorimotor dysfunction? Current Opinion in Neurobiology, 13 (2) , 212-218.

Ramus, F. (2005). Neurobiologie de la dyslexie développementale. Bulletin du cercle de Neurologie comportementale, 22, 12-13.

Seidenberg, M. S. \& McClelland, J. L. (1989). A distri- 
buted developmental model of word recognition. Psychological Review, 96, 523-568.

Seidenberg, M. S. (2007). Connectionist models of Reading. A G. Gaskell (Ed.), The Oxford Handbook of Psycholinguistics. Oxford: Oxford University Press, 235-250.

Seidenberg, M. S., Waters, G. S., Barnes, M. A. \& Tanenhaus, M. K. (1984). When does irregular spelling or pronuntiation influence word recognition?. Journal of verbal learning and verbal behavior, 23, 383-404.

Serra, M. (2013). Comunicación y lenguaje. La nueva neuropsicologia cognitiva (vol. 2). Barcelona: UBe.

Seymour, H. K. \& Duncan, L. G. (1997). Small versus Large Unit Theories of Reading Acquisition, Dyslexia, 3, 125-134.

Seymour, P. H. K., \& Evans, H. M. (1994). Levels of phonological awareness and learning to read. Reading and Writing, 6, 221-250.

Seymour, P. H. K., Aro, M. \& Erskine, J. M. (2003). Foundation literacy acquisition in European orthographies. British Journal of Psychology, 94, 143-174.

Seymour, P. H. K., Duncan, L. G., \& Bolik, F. M. (1999). Rhymes and phonemes in the common unit task: replications and implications for beginning reading. Journal of Research in Reading, 22(2), 113-130.

Share, D. L. (1995). Phonological recoding and selfteaching: sine qua non of reading acquisition. $\operatorname{Cog}$ nition, 55(2), 151-218.

Share, D. L. (1999). Phonological recoding and orthographic learning: A Direct Test of the self-teaching hypothesis: Journal of experimental child psychology, 72(2), 95-129.

Share, D. L. (2008). Orthographic learning, phonological recoding, and self-teaching. A R. Kail (Ed.) Advances in child development and behavior. Amsterdam: Elsevier.

Shaywitz, S. \& Shaywitz, B. A. (2005). Dyslexia (Speci- fic reading disability). Biological Psychiatry, 57, 13011309.

Shaywitz, S., Morris, R. \& Shaywitz, B. A. (2008). The education of dyslexic children from childhood to Young adulthood. Annual Review Psychology, 59, 451475.

Sprenger-Charrolles, L., Siegel, L.S., Jiménez, J. E. \& Ziegler, J. C. (2011). Prevalence and reliability of phonological, surface, and mixed profil-les in dyslexia: Areview of studies conducted in languages varying in orthographic depth. Scientific Studies of Reading, 15, 498-521.

Suárez, P. \& Cuetos, F. (2012). ¿Es la dislèxia un trastorno perceptivo-visual? Nuevos datos empíricos. Psicothema, 24, 188-192.

Procesos cognitivos que intervienen en el aprendizaje del lenguaje escrito y dislexia

Resumen. La lectura es una actividad compleja que involucra la interacción de dos procesos esenciales: el reconocimiento de palabras escritas y la comprensión. El primer proceso, a pesar de ser de nivel elemental, debe funcionar de manera óptima para que se pueda alcanzar el componente de más alto nivel que es la comprensión lectora. En este artículo se revisan los modelos cognitivos más relevantes que explican el reconocimiento de las palabras escritas y el acceso al léxico. En primer lugar se analiza la influencia que pueden ejercer factores como las características ortográficas de una lengua y las características de cada palabra en particular. En segundo lugar se hace una revisión del modelo de doble ruta y sus variaciones (Coltheart, 1981; Coltheart et al., 2001) y del modelo conexionista de Triángulo (Seidenberg \& McClelland, 1989; Seidenberg, 2007). Finalmente, se analiza la caracterización de la dislexia tomando como referencia las aportaciones de los modelos cognitivos.

Palabras clave: reconocimiento de palabras, acceso al léxico, lectura, modelos cognitivos, dislexia 